\title{
Obesogenic diet and physical activity: independent or associated behaviours in adolescents?
}

\author{
R Jago ${ }^{1, *}$, AR Ness ${ }^{2}$, P Emmett ${ }^{3}$, C Mattocks $^{4}$, L Jones $^{5}$ and CJ Riddoch ${ }^{4}$ \\ 'Department of Exercise, Nutrition \& Health Sciences, Centre for Sport, Exercise \& Health, University of Bristol, \\ Tyndall Avenue, Bristol BS8 1TP, UK: ${ }^{2}$ Department of Oral \& Dental Science, University of Bristol, Bristol, UK: \\ ${ }^{3}$ Department of Community-Based Medicine, University of Bristol, Bristol, UK: ${ }^{4}$ School for Health, University of \\ Bath, Bath, UK: ${ }^{5}$ Department of Social Medicine, University of Bristol, Bristol, UK
}

Submitted 7 November 2008: Accepted 20 0ctober 2009: First published online 3 December 2009

\begin{abstract}
Objective: Associations between diet and physical activity may identify behaviours that could be changed together to prevent childhood obesity. The present study examines associations between physical activity and obesogenic dietary behaviours in a large UK adolescent cohort.

Design: Cross-sectional analysis of a UK cohort. Adolescents aged 10-11 years completed three $1 \mathrm{~d}$ diet diaries. Average daily energy consumption, percentage energy from fat and carbohydrate, energy density and grams of fruit and vegetables were estimated. To assess physical activity participants wore an accelerometer for three or more days. Regression models were run by sex to examine the extent to which dietary variables predicted physical activity before and after controlling for pubertal status, maternal education and adiposity.

Setting: The Avon Longitudinal Study of Parents and Children (ALSPAC), southwest England.

Subjects: Adolescents who provided diet data at age 10 years and physical activity data at age 11 years.

Results: Among boys, percentage energy from fat was consistently negatively associated with accelerometer-determined indicators of physical activity (standardized beta $(\beta)=-0.055$ to $-0 \cdot 101, P<0 \cdot 05)$ while total energy $(\beta=0.066$ to $0 \cdot 091, P<0 \cdot 05)$ and percentage energy from carbohydrate $(\beta=0.054$ to $0 \cdot 106$, $P<0 \cdot 05)$ were positively associated before and after adjustment for confounders. For girls fruit and vegetable intake was consistently positively associated with physical activity $(\beta=0.056$ to $0 \cdot 074, P<0 \cdot 005)$. However all associations were weak. Associations were broadly comparable when participants with nonplausible dietary reports were included or excluded from the analyses.

Conclusions: Obesogenic diet and physical activity behaviours were weakly associated, suggesting that interventions should focus on implementing strategies that are independently successful at changing diet or physical activity behaviours either separately or in combination.
\end{abstract}

Children who are overweight are more likely to become overweight adults ${ }^{(1)}$. Obesity is the result of an imbalance between the energy consumed and the energy expen$\operatorname{ded}^{(2)}$. Dietary behaviours that have been positively associated with increased body mass among children include energy intake ${ }^{(3)}$, percentage energy from fat ${ }^{(3)}$ and energy density ${ }^{(4,5)}$, while fruit and vegetable intake has been negatively associated ${ }^{(6)}$. Ensuring that adolescents are physically active and consume a healthy diet is essential in preventing childhood obesity ${ }^{(7)}$.

Previous research among African-American girls aged 8-10 years showed that physical activity was negatively associated with percentage energy consumption from fat and positively associated with percentage energy from carbohydrate $^{(8)}$. These associations implied that interventions which attempt to change both behaviours by changing some underlying common construct may hold greater utility. It is not clear what such a construct may be, but it could be a personality trait, a desire to be healthy, living in a healthy environment, higher socio-economic status or an increased awareness of the importance of healthy eating and engaging in regular physical activity. Interventions designed to change both behaviours would be more effective if they attempted to manipulate the underlying construct, but before searching for the construct it is important to confirm if there are strong 
associations between adolescents' diet and physical activity behaviours. While associations between diet and physical activity have been reported among adults ${ }^{(9)}$, there is a shortage of findings among adolescents. Although previous research has shown a substantial percentage of participants are liable to misreport their dietary intake ${ }^{(10)}$ it is not clear if including these in analyses will affect associations between diet and physical activity. The aim of the present paper was to examine, in a large cohort of UK children, associations between the obesogenic aspects of diet and physical activity behaviours before and after accounting for misreporting of dietary intake. Furthermore, to examine if the accuracy of dietary reports affected the detected associations, all analyses were run for all participants and separately for just the participants who provided 'normal' or 'valid' reports of dietary intake.

\section{Methods}

Participants were adolescents aged 10-11 years from the Avon Longitudinal Study of Parents and Children (ALSPAC). As described elsewhere ${ }^{(11)}$, ALSPAC is a birth cohort study that recruited participants in the former British county of Avon in south-west England. A total of 14541 pregnant women were recruited into the original study, which resulted in 13988 children alive at 1 year. Data are presented here for children who provided diet data at age 10 years and physical activity data at 11 years. Ethical approval for the study was obtained from the ALSPAC Law and Ethics Committee and the local research ethics committees.

Participants provided three $1 \mathrm{~d}$ non-weighed diet diaries using methods that have been described in detail elsewhere and included an additional parent questionnaire and a brief interview which were used to clarify any issues that might have arisen ${ }^{(10,12)}$. Diet data were processed using methods similar to those previously described when the participants were aged 7 years ${ }^{(10)}$ and, to maximize the sample size, all participants with at least one day of data were included in the analysis. As the focus of the present paper is on dietary behaviours that have been associated with obesity, the following dietary variables were utilized: average energy consumed per day $(\mathrm{kJ} / \mathrm{kcal})$, percentage energy from fat, percentage energy from carbohydrate and mean grams of fruit and vegetables per day (excluding all juice, potatoes and baked beans). In addition, energy density (excluding drinks) was computed by dividing total food energy by total food weight.

Participants wore an MTI ActiGraph ${ }^{\text {TM }}$ model 7164 accelerometer (Manufacturing Technology Inc., Fort Walton Beach, FL, USA) for seven consecutive days ${ }^{(13)}$. The MTI ActiGraph has been shown to provide accurate and reliable assessments of physical activity in both children and adolescents ${ }^{(14,15)}$. Previous analysis of the data from the accelerometry study has shown that the reliability coefficient for $3 \mathrm{~d}$ of accelerometer monitoring was 0.7 within this cohort. Further analysis also indicated that there was a very small tendency for accelerometer counts to be higher on the first day of measurement when compared with the remaining days due to the novelty of the measurement, but this effect was very small (17 counts/min) and was less than $0 \cdot 1 \mathrm{sD}$ of usual monitoring days. Thus, including the first day of monitoring in analysis is unlikely to introduce bias into any analyses ${ }^{(16)}$. In light of this previous work participants were included in the present analyses if they provided three or more days of data with at least 600 min of data per day ${ }^{(16)}$. Mean counts per minute (CPM), an indication of the volume of physical activity, was calculated. To provide an indication of time spent engaged in moderate-to-vigorous physical activity (MVPA), the mean minutes per day in which there were more than 3600 accelerometer counts per minute was also calculated (Mean MVPA) and averaged $^{(17)}$. To assess if associations with dietary behaviours differed by week or weekend day, the mean minutes of MVPA per weekday (Weekday MVPA) and per weekend day (Weekend MVPA) were calculated with participants included in the analysis if they had at least one day of each assessment.

Maternal education was self-reported. Pubertal status was self-reported at age 10 and 11 years. Height was measured using a Harpenden stadiometer (Holtain, Crymych, UK), weight was measured using a Tanita TBF 305 body fat scale (Tanita, Tokyo, Japan) and BMI $\left(\mathrm{kg} / \mathrm{m}^{2}\right)$ at age 10 years was calculated. To facilitate international comparisons of the descriptive data, the International Obesity Taskforce (IOTF) criteria were used to classify participants as normal weight or overweight/obese ${ }^{(18)}$. As height has been associated with accelerometer energy expenditure $^{(19)}$ and pedometer step counts among adolescents $^{(20)}$, all of the regression models were adjusted for height. Fat mass was measured using a Lunar Prodigy DXA scanner (GE Medical Systems, Diegem, Belgium) at age 11 years. As total levels of fat mass increase with height it is important to account for stature when expressing an individual's level of adiposity, and therefore fat mass index (FMI; fat mass in kilograms divided by the square of height in metres) was calculated for all participants $^{(21-23)}$.

\section{Analysis}

Age-estimated BMR was calculated using the Schofield criteria $^{(24)}$. Using the same methods that have previously been applied to the diet data when the participants were 7 years of age ${ }^{(10)}$, the Torun criteria $^{(25)}$ were then used to identify likely misreporting of dietary intake and two samples, the full and restricted samples, were created. The full sample included participants with any diet data and at least $3 \mathrm{~d}$ of valid accelerometer data, while the restricted sample included participants who had 'plausible' 
Table 1 Participant characteristics by gender for full sample (diet data and at least $3 \mathrm{~d}$ of accelerometer data) and restricted sample (plausible diet data and at least $3 \mathrm{~d}$ of accelerometer data), Avon Longitudinal Study of Parents and Children (ALSPAC), south-west England

\begin{tabular}{|c|c|c|c|c|c|c|c|c|c|}
\hline & \multicolumn{4}{|c|}{ Full sample ( $n$ 5134) } & \multicolumn{4}{|c|}{ Restricted sample ( $n$ 3684) } & \multirow[b]{3}{*}{ Tests* } \\
\hline & \multicolumn{2}{|c|}{ Boys } & \multicolumn{2}{|c|}{ Girls } & \multicolumn{2}{|c|}{ Boys } & \multicolumn{2}{|c|}{ Girls } & \\
\hline & $n$ & $\%$ & $n$ & $\%$ & $n$ & $\%$ & $n$ & $\%$ & \\
\hline \multicolumn{10}{|l|}{ Pubertal stage (10) } \\
\hline 1 & 875 & $35 \cdot 6$ & 512 & $19 \cdot 1$ & 651 & $36 \cdot 2$ & 380 & $20 \cdot 6$ & \\
\hline 2 & 370 & $15 \cdot 0$ & 579 & $21 \cdot 6$ & 269 & $14 \cdot 9$ & 401 & $21 \cdot 7$ & \\
\hline 3 & 53 & $2 \cdot 2$ & 301 & $11 \cdot 2$ & 34 & 1.9 & 204 & $11 \cdot 1$ & \\
\hline 4 & 6 & $0 \cdot 2$ & 93 & $3 \cdot 5$ & 4 & $0 \cdot 2$ & 46 & $2 \cdot 5$ & \\
\hline 5 & 1 & $0 \cdot 0$ & 18 & $0 \cdot 7$ & 1 & $0 \cdot 1$ & 12 & $0 \cdot 7$ & $A, B, C$ \\
\hline Missing & 1149 & $46 \cdot 8$ & 1177 & $43 \cdot 9$ & 841 & $46 \cdot 7$ & 841 & $45 \cdot 6$ & \\
\hline \multicolumn{10}{|l|}{ Pubertal stage (11) } \\
\hline 1 & 510 & $20 \cdot 8$ & 195 & $7 \cdot 3$ & 375 & $20 \cdot 8$ & 148 & $8 \cdot 0$ & \\
\hline 2 & 563 & $22 \cdot 9$ & 624 & $23 \cdot 3$ & 426 & $23 \cdot 7$ & 443 & $24 \cdot 0$ & \\
\hline 3 & 200 & $8 \cdot 1$ & 713 & $26 \cdot 6$ & 132 & $7 \cdot 3$ & 499 & $27 \cdot 1$ & \\
\hline 4 & 54 & $2 \cdot 2$ & 380 & $14 \cdot 2$ & 41 & $2 \cdot 3$ & 547 & $29 \cdot 7$ & \\
\hline 5 & 2 & $0 \cdot 0$ & 107 & $4 \cdot 0$ & 2 & $0 \cdot 1$ & 65 & $3 \cdot 5$ & $A, B, C$ \\
\hline Missing & 1125 & $45 \cdot 8$ & 661 & $24 \cdot 7$ & 824 & $45 \cdot 8$ & 182 & $9 \cdot 9$ & \\
\hline \multicolumn{10}{|l|}{ IOTF (10) } \\
\hline Normal & 2000 & $81 \cdot 9$ & 2079 & $78 \cdot 0$ & 1580 & $87 \cdot 8$ & 1569 & $83 \cdot 2$ & \\
\hline Overweight/obese & 443 & $18 \cdot 1$ & 586 & $22 \cdot 0$ & 213 & $11 \cdot 8$ & 304 & $16 \cdot 1$ & A, B, C \\
\hline \multicolumn{10}{|l|}{ IOTF (11) } \\
\hline Normal & 1960 & $80 \cdot 7$ & 2056 & $77 \cdot 7$ & 1543 & $85 \cdot 7$ & 1534 & $81 \cdot 4$ & \\
\hline Overweight/obese & 469 & $19 \cdot 3$ & 591 & $22 \cdot 3$ & 240 & $13 \cdot 3$ & 330 & $17 \cdot 6$ & $A, B, C$ \\
\hline Under-report of diet & 541 & $22 \cdot 0$ & 728 & $27 \cdot 2$ & NA & NA & NA & NA & \\
\hline Normal diet report & 1800 & $73 \cdot 3$ & 1884 & $70 \cdot 3$ & NA & NA & NA & NA & \\
\hline \multirow[t]{2}{*}{ Over-report of diet } & 113 & $4 \cdot 6$ & 68 & $2 \cdot 5$ & NA & NA & NA & NA & A \\
\hline & Mean & SD & Mean & SD & Mean & SD & Mean & SD & \\
\hline Height (10) (cm) & $143 \cdot 8$ & $6 \cdot 4$ & $143 \cdot 9$ & $6 \cdot 9$ & $143 \cdot 4$ & $6 \cdot 3$ & $143 \cdot 5$ & $6 \cdot 7$ & $\mathrm{C}$ \\
\hline Height (11) (cm) & $150 \cdot 6$ & $7 \cdot 0$ & $151 \cdot 3$ & $7 \cdot 2$ & $149 \cdot 6$ & $7 \cdot 0$ & $151 \cdot 6$ & $7 \cdot 2$ & $A, B, C$ \\
\hline BMI (10) $\left(\mathrm{kg} / \mathrm{m}^{2}\right)$ & $18 \cdot 0$ & $3 \cdot 0$ & $18 \cdot 4$ & $3 \cdot 2$ & $17 \cdot 4$ & $2 \cdot 3$ & $17 \cdot 8$ & $2 \cdot 7$ & $A, B, C$ \\
\hline BMI (11) $\left(\mathrm{kg} / \mathrm{m}^{2}\right)$ & $18 \cdot 7$ & $3 \cdot 2$ & $19 \cdot 3$ & $3 \cdot 5$ & $18 \cdot 1$ & $2 \cdot 6$ & $18 \cdot 7$ & $3 \cdot 0$ & $A, B, C$ \\
\hline FMI $\left(\mathrm{kg} / \mathrm{m}^{2}\right)$ & $4 \cdot 5$ & $2 \cdot 7$ & $5 \cdot 6$ & $2 \cdot 7$ & $4 \cdot 0$ & $2 \cdot 1$ & $5 \cdot 1$ & $2 \cdot 4$ & A, B, C \\
\hline CPM & $664 \cdot 3$ & $190 \cdot 8$ & $552 \cdot 2$ & $156 \cdot 0$ & $670 \cdot 4$ & $186 \cdot 6$ & $555 \cdot 1$ & $151 \cdot 7$ & $A, B, C$ \\
\hline Mean MVPA $(\min / \mathrm{d})$ & $28 \cdot 5$ & $17 \cdot 0$ & $18 \cdot 2$ & $11 \cdot 8$ & $29 \cdot 3$ & $17 \cdot 0$ & $18 \cdot 5$ & $11 \cdot 8$ & $A, B, C$ \\
\hline Weekday MVPA (min/d) & $30 \cdot 0$ & $18 \cdot 6$ & $19 \cdot 05$ & $12 \cdot 8$ & $30 \cdot 7$ & $18 \cdot 7$ & $19 \cdot 4$ & $12 \cdot 8$ & A, B, C \\
\hline Weekend MVPA (min/d) & $23 \cdot 5$ & $20 \cdot 3$ & $15 \cdot 0$ & $14 \cdot 9$ & $24 \cdot 4$ & $20 \cdot 9$ & $15 \cdot 4$ & $15 \cdot 3$ & $A, B, C$ \\
\hline Energy (kJ) & 8168 & 1640 & 7403 & 1458 & 8509 & 1168 & 7871 & 1033 & A, B, C \\
\hline Energy (kcal) & $1952 \cdot 3$ & $392 \cdot 0$ & $1769 \cdot 3$ & $348 \cdot 4$ & $2033 \cdot 6$ & $279 \cdot 1$ & $1881 \cdot 1$ & $246 \cdot 9$ & $A, B, C$ \\
\hline$\%$ Energy from fat & $36 \cdot 2$ & $4 \cdot 9$ & $36 \cdot 7$ & $4 \cdot 8$ & $36 \cdot 4$ & $4 \cdot 7$ & $36 \cdot 9$ & $4 \cdot 5$ & $A, B, C$ \\
\hline$\%$ Energy from carbohydrate & $53 \cdot 6$ & $5 \cdot 4$ & $53 \cdot 4$ & $5 \cdot 4$ & $53 \cdot 8$ & $5 \cdot 3$ & $53 \cdot 4$ & $5 \cdot 1$ & $\mathrm{~B}, \mathrm{C}$ \\
\hline Energy density $(\mathrm{kJ} / \mathrm{g})$ & $8 \cdot 8$ & $1 \cdot 6$ & $8 \cdot 6$ & $1 \cdot 6$ & $8 \cdot 9$ & $1 \cdot 5$ & $8 \cdot 7$ & $1 \cdot 5$ & $A, B, C$ \\
\hline Fruit \& vegetables $(\mathrm{g} / \mathrm{d})$ & $136 \cdot 0$ & $109 \cdot 7$ & $147 \cdot 1$ & $106 \cdot 7$ & $141 \cdot 0$ & $108 \cdot 9$ & $152 \cdot 5$ & $109 \cdot 2$ & $A, B, C$ \\
\hline
\end{tabular}

(10), assessment at age 10 years; (11), assessment at age 11 years; IOTF, International Obesity Taskforce; FMI, fat mass index; CPM, counts per minute; MVPA, moderate-to-vigorous physical activity; NA, not applicable.

${ }^{*} \mathrm{~A}=$ sex difference $(P<0.05)$ in full sample; $\mathrm{B}=$ sex difference $(P<0.05)$ in restricted sample; $\mathrm{C}=$ difference $(P<0.05)$ for participants in restricted and full sample.

dietary reports and at least $3 \mathrm{~d}$ of accelerometer data. The $\chi^{2}$ test was used to examine sex differences in pubertal status and IOTF categories of obesity (at age 10 and 11 years) for both samples. The $\chi^{2}$ test was then used to examine if there were differences in pubertal status or IOTF groups between the samples (i.e. comparing normal dietary reporters $v$. all other participant groups). For the full sample one-way ANOVA tests were performed with sex as a factor investigating the following variables: BMI, FMI, CPM, Mean MVPA, Weekday MVPA, Weekend MVPA, energy, percentage energy from fat, percentage energy from carbohydrate, height, energy density and grams of fruit and vegetables per day. This process was then repeated using the restricted sample.
As the diet and physical activity assessments were made a year apart the month of each assessment was coded as spring (March, April, May), summer (June, July, August), autumn (September, October, November) or winter (December, January, February). The two assessments were then compared and a dummy variable created to take account of the $59 \cdot 9 \%$ of physical activity assessments conducted in a different season to the dietary assessments. Linear regression models were used to examine the extent to which dietary variables (energy, percentage energy from carbohydrate, percentage energy from fat, energy density, fruit and vegetable consumption) predicted each of the four physical activity outcome variables. Models were run in five steps for each 
Table 2 Association between mean CPM per day and dietary variables in 11-year-old children (restricted to plausible reporters of dietary intake only), Avon Longitudinal Study of Parents and Children (ALSPAC), south-west England

\begin{tabular}{|c|c|c|c|c|c|c|c|c|c|}
\hline \multirow[b]{2}{*}{ Exposure } & \multirow[b]{2}{*}{ Model no. } & \multicolumn{4}{|c|}{ Boys } & \multicolumn{4}{|c|}{ Girls } \\
\hline & & $B$ & $95 \% \mathrm{Cl}$ & $\beta$ & $P$ & $B$ & $95 \% \mathrm{Cl}$ & $\beta$ & $P$ \\
\hline Total energy (kJ) & $\begin{array}{l}1 \\
2 \\
3 \\
4 \\
5\end{array}$ & $\begin{array}{l}0.015 \\
0.061 \\
0.060 \\
0.047 \\
0.045\end{array}$ & $\begin{array}{r}-0.016,0.046 \\
0.027,0.095 \\
0.014,0.105 \\
0.013,0.082 \\
-0.001,0.091\end{array}$ & $\begin{array}{l}0.022 \\
0.091 \\
0.090 \\
0.071 \\
0.068\end{array}$ & $\begin{array}{r}0.345 \\
<0.001 \\
0.010 \\
0.007 \\
0.055\end{array}$ & $\begin{array}{r}-0.028 \\
0.017 \\
0.044 \\
0.002 \\
0.032\end{array}$ & $\begin{array}{r}-0.055,0.000 \\
-0.014,0.049 \\
0.008,0.080 \\
-0.029,0.034 \\
-0.004,0.068\end{array}$ & $\begin{array}{r}-0.045 \\
0.029 \\
0.072 \\
0.004 \\
0.052\end{array}$ & $\begin{array}{l}0.052 \\
0.276 \\
0.017 \\
0.893 \\
0.084\end{array}$ \\
\hline$\%$ Energy from carbohydrate & $\begin{array}{l}1 \\
2 \\
3 \\
4 \\
5\end{array}$ & $\begin{array}{l}2 \cdot 269 \\
1 \cdot 871 \\
1 \cdot 904 \\
2 \cdot 257 \\
2 \cdot 313\end{array}$ & $\begin{array}{r}0.637,3.901 \\
0.231,3.512 \\
-0.381,4.189 \\
0.605,3.909 \\
0.003,4.624\end{array}$ & $\begin{array}{l}0.064 \\
0.054 \\
0.053 \\
0.064 \\
0.065\end{array}$ & $\begin{array}{l}0.006 \\
0.025 \\
0 \cdot 102 \\
0.007 \\
0.050\end{array}$ & $\begin{array}{l}0 \cdot 151 \\
0.367 \\
0.367 \\
0.562 \\
0.612\end{array}$ & $\begin{array}{l}-1 \cdot 187,1 \cdot 489 \\
-0.995,1 \cdot 729 \\
-1 \cdot 200,1.933 \\
-0.818,1.941 \\
-0.972,2 \cdot 197\end{array}$ & $\begin{array}{l}0.005 \\
0.013 \\
0.013 \\
0.019 \\
0.021\end{array}$ & $\begin{array}{l}0.825 \\
0.597 \\
0.646 \\
0.424 \\
0.448\end{array}$ \\
\hline$\%$ Energy from fat & $\begin{array}{l}1 \\
2 \\
3 \\
4 \\
5\end{array}$ & $\begin{array}{l}-2 \cdot 198 \\
-1 \cdot 724 \\
-1 \cdot 505 \\
-2 \cdot 215 \\
-1 \cdot 955\end{array}$ & $\begin{array}{l}-4 \cdot 048,-0 \cdot 348 \\
-3 \cdot 593,0 \cdot 144 \\
-4 \cdot 100,1 \cdot 090 \\
-4 \cdot 0494,-0 \cdot 355 \\
-4 \cdot 617,0 \cdot 627\end{array}$ & $\begin{array}{l}-0.055 \\
-0.043 \\
-0.037 \\
-0.056 \\
-0.049\end{array}$ & $\begin{array}{l}0.020 \\
0 \cdot 070 \\
0 \cdot 255 \\
0.021 \\
0 \cdot 136\end{array}$ & $\begin{array}{r}0.492 \\
0.454 \\
0.216 \\
0.291 \\
-0.006\end{array}$ & $\begin{array}{l}-1 \cdot 017,2 \cdot 000 \\
-1.086,1.993 \\
-1 \cdot 558,1.989 \\
-1.267,1.849 \\
-1 \cdot 797,1.785\end{array}$ & $\begin{array}{l}0.015 \\
0.014 \\
0.007 \\
0.009 \\
0.000\end{array}$ & $\begin{array}{l}0.523 \\
0.563 \\
0.811 \\
0.714 \\
0.995\end{array}$ \\
\hline Energy density & $\begin{array}{l}1 \\
2 \\
3 \\
4 \\
5\end{array}$ & $\begin{array}{r}-0.828 \\
0.438 \\
3.800 \\
-0.559 \\
3.710\end{array}$ & $\begin{array}{l}-6 \cdot 423,4 \cdot 767 \\
-5 \cdot 292,6 \cdot 168 \\
-3 \cdot 981,11 \cdot 581 \\
-6 \cdot 335,5 \cdot 218 \\
-4 \cdot 163,11 \cdot 584\end{array}$ & $\begin{array}{r}-0.007 \\
0.004 \\
0.031 \\
-0.005 \\
0.031\end{array}$ & $\begin{array}{l}0.772 \\
0.881 \\
0.338 \\
0.850 \\
0.355\end{array}$ & $\begin{array}{r}1 \cdot 087 \\
1 \cdot 222 \\
0.278 \\
0 \cdot 414 \\
-0.439\end{array}$ & $\begin{array}{r}-3 \cdot 470,5 \cdot 644 \\
-3 \cdot 535,5 \cdot 980 \\
-5 \cdot 227,5 \cdot 783 \\
-4 \cdot 396,5 \cdot 224 \\
6 \cdot 003,5 \cdot 124\end{array}$ & $\begin{array}{r}0.011 \\
0.012 \\
0.003 \\
0.004 \\
-0.004\end{array}$ & $\begin{array}{l}0.640 \\
0 \cdot 614 \\
0.921 \\
0 \cdot 866 \\
0 \cdot 877\end{array}$ \\
\hline Fruit \& vegetables* & $\begin{array}{l}1 \\
2 \\
3 \\
4 \\
5\end{array}$ & $\begin{array}{l}-0.008 \\
-0.018 \\
-0.031 \\
-0.022 \\
-0.028\end{array}$ & $\begin{array}{l}-0.088,0.072 \\
-0.101,0.064 \\
-0.146,0.083 \\
-0.086,0.081 \\
-0.144,0.088\end{array}$ & $\begin{array}{l}-0.005 \\
-0.011 \\
-0.018 \\
-0.001 \\
-0.016\end{array}$ & $\begin{array}{l}0.842 \\
0.663 \\
0.591 \\
0.961 \\
0.635\end{array}$ & $\begin{array}{l}0.043 \\
0.043 \\
0.080 \\
0.055 \\
0.091\end{array}$ & $\begin{array}{r}10 \cdot 020,0 \cdot 106 \\
-0.025,0 \cdot 111 \\
0.001,0 \cdot 160 \\
-0.014,0 \cdot 124 \\
0.010,0 \cdot 171\end{array}$ & $\begin{array}{l}0.031 \\
0.030 \\
0.056 \\
0.039 \\
0.062\end{array}$ & $\begin{array}{l}0 \cdot 183 \\
0 \cdot 217 \\
0.047 \\
0 \cdot 116 \\
0 \cdot 027\end{array}$ \\
\hline
\end{tabular}

CPM, counts per minute; $B$, unstandardized beta; $\beta$, standardized beta.

Model $1=$ unadjusted; Model $2=$ Model 1 plus maternal education, fat mass index, height and season change; Model $3=$ Model 2 plus pubertal status; Model 4 = Model 1 plus maternal education, International Obesity Taskforce group (reference normal), height and season change; Model $5=$ Model 4 plus pubertal status. ${ }^{*}$ All fruit and vegetable models are also adjusted for total energy consumption.

outcome: Model 1, exposure variable only; Model 2, Model 1 plus maternal education, FMI, height and season change; Model 3, Model 2 plus pubertal status at age 11 years (when the outcome was assessed); Model 4, as Model 2 but with IOTF category at age 11 years (overweight/obese with normal as the reference group) instead of FMI; Model 5, Model 4 plus pubertal status. All fruit and vegetable models also controlled for total energy consumed. As preliminary analyses indicated there was strong evidence $(P<0 \cdot 001)$ of sex differences in outcome and exposure variables, all models were run separately by sex. Analyses were performed separately for the full and restricted samples using the SPSS statistical software package version $14 \cdot 0$ (SPSS Inc., Chicago, IL, USA) and $\alpha$ was set at $0 \cdot 05$.

\section{Results}

There were 5134 participants in the full sample and 3684 in the restricted sample. For the full sample $20 \cdot 1 \%$ of the participants were overweight or obese based on the IOTF criteria at 10 years of age. The $\chi^{2}$ tests indicated sex differences in pubertal status both at age 10 and 11 years, with more girls being classified with higher Tanner stage scores than the boys using both the full and restricted samples. For the full sample, Tanner stage data were missing for $46.8 \%$ of males and $43.9 \%$ of females at age 10 years and $45 \cdot 8 \%$ of males and $24.7 \%$ females at age 11 years, with similar proportions in the restricted sample (Table 1).

In the full sample, girls' FMI was higher than that of the boys $\left(5 \cdot 6 v .4 .5 \mathrm{~kg} / \mathrm{m}^{2}, P<0 \cdot 001\right)$ with a similar pattern in the restricted sample $\left(5 \cdot 1 v \cdot 4 \cdot 0 \mathrm{~kg} / \mathrm{m}^{2}, P<0 \cdot 001\right)$. Participants in the full sample were slightly taller than participants in the restricted sample at age 10 years $(144 \cdot 7 v$. $143.5 \mathrm{~cm})$ and at age 11 years $(151.5 v .150 \cdot 4 \mathrm{~cm})$. FMI was lower in the restricted sample than in the full sample $\left(4.6 v .6 \cdot 2 \mathrm{~kg} / \mathrm{m}^{2}\right)$. For the full sample CPM was higher among the boys than the girls $(664 \cdot 3 v .552 \cdot 2)$ as were Mean MVPA (28.5 v.18.2 min/d), Weekday MVPA (30.0 $v$. $19.05 \mathrm{~min} / \mathrm{d})$ and Weekend MVPA $(23.5 v .15 .0 \mathrm{~min} / \mathrm{d})$, with similar results for the restricted sample (all $P<0 \cdot 005)$. All physical activity variables were higher in the restricted sample $(P<0 \cdot 005)$.

There was a sex difference in the energy consumption of participants in the full sample, with higher consumption among the boys $(8168 v .7403 \mathrm{~kJ} / \mathrm{d}(1952 \cdot 3 v$. $1769 \cdot 3 \mathrm{kcal} / \mathrm{d})$ ). Girls in the full sample consumed a greater percentage of their energy from fat than the boys 
Table 3 Association between Mean MVPA ( $\mathrm{min} / \mathrm{d}$ ) and dietary variables in 11-year-old children (restricted to plausible reporters of dietary intake only), Avon Longitudinal Study of Parents and Children (ALSPAC), south-west England

\begin{tabular}{|c|c|c|c|c|c|c|c|c|c|}
\hline \multirow[b]{2}{*}{ Exposure } & \multirow[b]{2}{*}{ Model no. } & \multicolumn{4}{|c|}{ Boys } & \multicolumn{4}{|c|}{ Girls } \\
\hline & & $B$ & $95 \% \mathrm{Cl}$ & $\beta$ & $P$ & $B$ & $95 \% \mathrm{Cl}$ & $\beta$ & $P$ \\
\hline Total energy (kJ) & $\begin{array}{l}1 \\
2 \\
3 \\
4 \\
5\end{array}$ & $\begin{array}{l}0.001 \\
0.004 \\
0.004 \\
0.003 \\
0.003\end{array}$ & $\begin{array}{r}-0.002,0.004 \\
0.001,0.007 \\
0.000,0.008 \\
0.000,0.006 \\
0.002,0.007\end{array}$ & $\begin{array}{l}0.013 \\
0.066 \\
0.068 \\
0.044 \\
0.044\end{array}$ & $\begin{array}{l}0.577 \\
0.011 \\
0.052 \\
0.097 \\
0.216\end{array}$ & $\begin{array}{r}-0.002 \\
0.000 \\
0.003 \\
-0.001 \\
0.002\end{array}$ & $\begin{array}{r}-0.004,0.001 \\
-0.002,0.003 \\
0.000,0.005 \\
-0.003,0.002 \\
-0.001,0.004\end{array}$ & $\begin{array}{r}-0.035 \\
0.006 \\
0.054 \\
-0.019 \\
0.033\end{array}$ & $\begin{array}{l}0 \cdot 132 \\
0 \cdot 830 \\
0 \cdot 074 \\
0 \cdot 464 \\
0 \cdot 271\end{array}$ \\
\hline$\%$ Energy from carbohydrate & $\begin{array}{l}1 \\
2 \\
3 \\
4 \\
5\end{array}$ & $\begin{array}{l}0.219 \\
0.180 \\
0.313 \\
0.221 \\
0.349\end{array}$ & $\begin{array}{l}0.071,0.368 \\
0.029,0.330 \\
0.102,0.524 \\
0.069,0.373 \\
0.135,0.563\end{array}$ & $\begin{array}{l}0.068 \\
0.056 \\
0.095 \\
0.069 \\
0.106\end{array}$ & $\begin{array}{l}0.004 \\
0.020 \\
0.004 \\
0.004 \\
0.001\end{array}$ & $\begin{array}{l}0.021 \\
0.033 \\
0.037 \\
0.050 \\
0.060\end{array}$ & $\begin{array}{l}-0.083,0.125 \\
-0.073,0.139 \\
-0.084,0.159 \\
-0.058,0.158 \\
-0.063,0.184\end{array}$ & $\begin{array}{l}0.009 \\
0.015 \\
0.017 \\
0.022 \\
0.026\end{array}$ & $\begin{array}{l}0.692 \\
0.541 \\
0.547 \\
0.361 \\
0.338\end{array}$ \\
\hline$\%$ Energy from fat & $\begin{array}{l}1 \\
2 \\
3 \\
4 \\
5\end{array}$ & $\begin{array}{l}-0.232 \\
-0.179 \\
-0.321 \\
-0.235 \\
-0.366\end{array}$ & $\begin{array}{l}-0.401,-0.064 \\
-0.350,-0.007 \\
-0.561,-0.082 \\
-0.408,-0.061 \\
-0.609,-0.124\end{array}$ & $\begin{array}{l}-0.064 \\
-0.088 \\
-0.086 \\
-0.065 \\
-0.098\end{array}$ & $\begin{array}{l}0.007 \\
0.041 \\
0.009 \\
0.008 \\
0.003\end{array}$ & $\begin{array}{r}0.023 \\
0.020 \\
-0.011 \\
0.005 \\
-0.033\end{array}$ & $\begin{array}{l}-0 \cdot 095,0 \cdot 140 \\
-0 \cdot 100,0 \cdot 139 \\
-0 \cdot 149,0 \cdot 126 \\
-0 \cdot 117,0 \cdot 127 \\
-0 \cdot 172,0 \cdot 107\end{array}$ & $\begin{array}{r}0.009 \\
0.008 \\
-0.004 \\
0.002 \\
-0.013\end{array}$ & $\begin{array}{l}0 \cdot 707 \\
0 \cdot 750 \\
0 \cdot 873 \\
0.940 \\
0.646\end{array}$ \\
\hline Energy density & $\begin{array}{l}1 \\
2 \\
3 \\
4 \\
5\end{array}$ & $\begin{array}{r}-0.180 \\
0.044 \\
0.125 \\
-0.048 \\
0.160\end{array}$ & $\begin{array}{l}10.691,0.330 \\
-0.483,0.570 \\
-0.595,0.846 \\
-0.581,0.484 \\
-0.572,0.891\end{array}$ & $\begin{array}{r}-0.016 \\
0.004 \\
0.011 \\
-0.004 \\
0.014\end{array}$ & $\begin{array}{l}0.489 \\
0.871 \\
0.733 \\
0.858 \\
0.669\end{array}$ & $\begin{array}{l}-0.127 \\
-0.044 \\
-0.134 \\
-0.107 \\
-0.191\end{array}$ & $\begin{array}{r}0.482,0.228 \\
-0.414,0.327 \\
-0.580,0.293 \\
-0.484,0.270 \\
-0.624,0.243\end{array}$ & $\begin{array}{l}-0.016 \\
-0.006 \\
-0.017 \\
-0.014 \\
-0.024\end{array}$ & $\begin{array}{l}0.482 \\
0.817 \\
0.538 \\
0.578 \\
0.389\end{array}$ \\
\hline Fruit \& vegetables* & $\begin{array}{l}1 \\
2 \\
3 \\
4 \\
5\end{array}$ & $\begin{array}{r}0.002 \\
-0.001 \\
-0.001 \\
0.000 \\
-0.001\end{array}$ & $\begin{array}{l}-0.006,0.009 \\
-0.009,0.006 \\
-0.012,0.010 \\
-0.007,0.008 \\
-0.012,0.010\end{array}$ & $\begin{array}{r}0.011 \\
-0.008 \\
-0.006 \\
0.002 \\
-0.005\end{array}$ & $\begin{array}{l}0.639 \\
0.737 \\
0.865 \\
0.920 \\
0.875\end{array}$ & $\begin{array}{l}0.006 \\
0.005 \\
0.008 \\
0.006 \\
0.008\end{array}$ & $\begin{array}{r}0.001,0.011 \\
-0.001,0.010 \\
0.001,0.014 \\
0.000,0.011 \\
0.002,0.015\end{array}$ & $\begin{array}{l}0.057 \\
0.041 \\
0.068 \\
0.050 \\
0.074\end{array}$ & $\begin{array}{l}0.015 \\
0.090 \\
0.016 \\
0.044 \\
0.009\end{array}$ \\
\hline
\end{tabular}

MVPA, moderate-to-vigorous physical activity; $B$, unstandardized beta; $\beta$, standardized beta.

Model $1=$ unadjusted; Model $2=$ Model 1 plus maternal education, fat mass index, height and season change; Model $3=$ Model 2 plus pubertal status; Model 4 = Model 1 plus maternal education, International Obesity Taskforce group (reference normal), height and season change; Model $5=$ Model 4 plus pubertal status. ${ }^{*}$ All fruit and vegetable models are also adjusted for total energy consumption.

$(36 \cdot 7 \%$ v. $36 \cdot 2 \%)$, with comparable findings in the restricted sample. Boys in the restricted sample consumed a greater percentage of their energy from carbohydrate than girls $(53.8 \% v .53 \cdot 4 \%)$. Girls in the full sample consumed a greater weight of fruit and vegetables per day than boys $(147 \cdot 1 v .136 \cdot 0 \mathrm{~g} / \mathrm{d})$ with a similar result in the restricted sample $(152.5$ v. $141 \cdot 0 \mathrm{~g} / \mathrm{d})$.

Regression models in which each of the dietary variables predicted CPM are shown by sex in the restricted sample in Table 2. Total energy was associated with CPM among boys in models that adjusted for confounders; however, the associations were weak (standardized beta $(\beta)=0.071$ to $0 \cdot 091)$. Percentage energy from carbohydrate was positively associated with CPM in boys in the unadjusted model (unstandardized beta $(B)=2 \cdot 269 ; 95 \%$ CI $0 \cdot 637,3 \cdot 901 ; P=0 \cdot 006)$ and this pattern was still evident after adjustment for confounders but not when the model was also adjusted for pubertal status (Models 3 and 5). Percentage energy from fat was negatively associated with CPM among boys in the unadjusted model (Model 1: $B=-2 \cdot 198 ; 95 \%$ CI $-4 \cdot 048,-0 \cdot 348 ; P=0 \cdot 020)$ but only remained associated in the model that adjusted for IOTF thresholds instead of FMI (Model 4). For girls fruit and vegetable consumption was associated with CPM after adjusting for all confounders and pubertal status
$(B=0 \cdot 080 ; 95 \%$ CI $0 \cdot 001,0 \cdot 160 ; P=0 \cdot 047)$ with a similar pattern evident when the IOTF cut-off point was used instead of FMI (Table 2).

Among boys percentage energy from carbohydrate was positively associated with Mean MVPA in all of the models $(\beta=0.056$ to $0 \cdot 106)$ while percentage energy from fat was negatively associated in all of the models $(\beta=-0.064$ to $-0 \cdot 098)$. Among girls fruit and vegetable consumption was positively associated with Mean MVPA in all of the models ( $\beta=0 \cdot 041$ to $0 \cdot 074$; Table 3$)$. A similar pattern was evident for both genders when Weekday MVPA was the outcome (Table 4). When Weekend MVPA was the outcome (Table 5) fruit and vegetable intake was associated with physical activity among the girls but only in the models that controlled for all confounders and pubertal status (Models 3 and 5).

In the full sample, total energy consumption was associated with CPM among girls in the two models (3 and 5) that adjusted for pubertal status $(\beta=0.065$ and $0 \cdot 069)$, with fruit and vegetable consumption also associated with physical activity but only after adjusting for pubertal status $(\beta=0.047$ and $0 \cdot 046)$. For boys total energy was associated with CPM in all of the models but was only associated with percentage energy from carbohydrate in the unadjusted model (Model 1: $B=1 \cdot 394$; 
Table 4 Association between Weekday MVPA $(\mathrm{min} / \mathrm{d})$ and dietary variables in 11-year-old children (restricted, plausible reporters of dietary intake only), Avon Longitudinal Study of Parents and Children (ALSPAC), south-west England

\begin{tabular}{|c|c|c|c|c|c|c|c|c|c|}
\hline \multirow[b]{2}{*}{ Exposure } & \multirow[b]{2}{*}{ Model no. } & \multicolumn{4}{|c|}{ Boys } & \multicolumn{4}{|c|}{ Girls } \\
\hline & & $B$ & $95 \% \mathrm{Cl}$ & $\beta$ & $P$ & $B$ & $95 \% \mathrm{Cl}$ & $\beta$ & $P$ \\
\hline Total energy (kJ) & $\begin{array}{l}1 \\
2 \\
3 \\
4 \\
5\end{array}$ & $\begin{array}{l}0.001 \\
0.005 \\
0.005 \\
0.003 \\
0.004\end{array}$ & $\begin{array}{r}-0.022,0.005 \\
0.001,0.008 \\
0.001,0.010 \\
0.000,0.007 \\
-0.001,0.008\end{array}$ & $\begin{array}{l}0.022 \\
0.073 \\
0.079 \\
0.049 \\
0.057\end{array}$ & $\begin{array}{l}0.344 \\
0.006 \\
0.024 \\
0.063 \\
0.108\end{array}$ & $\begin{array}{r}-0.022 \\
0.000 \\
0.002 \\
-0.001 \\
0.001\end{array}$ & $\begin{array}{l}-0.044,0.000 \\
-0.002,0.003 \\
-0.001,0.005 \\
-0.004,0.002 \\
-0.002,0.004\end{array}$ & $\begin{array}{r}-0.036 \\
0.003 \\
0.048 \\
-0.020 \\
0.028\end{array}$ & $\begin{array}{l}0 \cdot 118 \\
0 \cdot 896 \\
0 \cdot 114 \\
0 \cdot 448 \\
0 \cdot 346\end{array}$ \\
\hline$\%$ Energy from carbohydrate & $\begin{array}{l}1 \\
2 \\
3 \\
4 \\
5\end{array}$ & $\begin{array}{l}0.235 \\
0.190 \\
0.340 \\
0.231 \\
0.372\end{array}$ & $\begin{array}{l}0.071,0.398 \\
0.024,0.357 \\
0.109,0.570 \\
0.063,0.399 \\
0.139,0.605\end{array}$ & $\begin{array}{l}0.066 \\
0.054 \\
0.094 \\
0.066 \\
0.103\end{array}$ & $\begin{array}{l}0.005 \\
0.025 \\
0.004 \\
0.007 \\
0.002\end{array}$ & $\begin{array}{l}0.018 \\
0.027 \\
0.040 \\
0.044 \\
0.064\end{array}$ & $\begin{array}{l}-0.095,0.131 \\
-0.087,0.142 \\
-0.090,0.171 \\
-0.072,0.160 \\
-0.068,0.197\end{array}$ & $\begin{array}{l}0.007 \\
0.011 \\
0.017 \\
0.018 \\
0.026\end{array}$ & $\begin{array}{l}0.752 \\
0.639 \\
0.545 \\
0.458 \\
0.340\end{array}$ \\
\hline$\%$ Energy from fat & $\begin{array}{l}1 \\
2 \\
3 \\
4 \\
5\end{array}$ & $\begin{array}{l}-0.244 \\
-0.195 \\
-0.371 \\
-0.250 \\
-0.412\end{array}$ & $\begin{array}{l}-0.429,-0.059 \\
-0.385,-0.006 \\
-0.633,-0.109 \\
-0.441,-0.060 \\
-0.676,-0.148\end{array}$ & $\begin{array}{l}-0.061 \\
-0.049 \\
-0.091 \\
-0.063 \\
-0.101\end{array}$ & $\begin{array}{l}0.010 \\
0.044 \\
0.005 \\
0.010 \\
0.002\end{array}$ & $\begin{array}{r}0.023 \\
0.024 \\
-0.020 \\
0.009 \\
-0.043\end{array}$ & $\begin{array}{l}-0 \cdot 105,0 \cdot 150 \\
-0 \cdot 105,0 \cdot 154 \\
-0 \cdot 168,0 \cdot 126 \\
-0 \cdot 122,0 \cdot 140 \\
-0 \cdot 193,0 \cdot 106\end{array}$ & $\begin{array}{r}0.008 \\
0.009 \\
-0.007 \\
0.003 \\
-0.016\end{array}$ & $\begin{array}{l}0.725 \\
0.716 \\
0.792 \\
0.893 \\
0.570\end{array}$ \\
\hline Energy density & $\begin{array}{l}1 \\
2 \\
3 \\
4 \\
5\end{array}$ & $\begin{array}{r}-0.029 \\
0.219 \\
0.183 \\
0.129 \\
0.227\end{array}$ & $\begin{array}{l}-0.589,0.532 \\
-0.362,0.801 \\
-0.605,0.970 \\
-0.457,0.716 \\
-0.570,1.024\end{array}$ & $\begin{array}{r}-0.002 \\
0.018 \\
0.015 \\
0.011 \\
0.019\end{array}$ & $\begin{array}{l}0.920 \\
0.459 \\
0.649 \\
0.666 \\
0.576\end{array}$ & $\begin{array}{l}-0.155 \\
-0.066 \\
-0.151 \\
-0.127 \\
-0.214\end{array}$ & $\begin{array}{l}-0.540,0.230 \\
-0.467,0.334 \\
-0.610,0.308 \\
-0.532,0.279 \\
-0.678,0.251\end{array}$ & $\begin{array}{l}-0.018 \\
-0.008 \\
-0.018 \\
-0.015 \\
-0.025\end{array}$ & $\begin{array}{l}0.430 \\
0.745 \\
0.518 \\
0.540 \\
0.368\end{array}$ \\
\hline Fruit \& vegetables* & $\begin{array}{l}1 \\
2 \\
3 \\
4 \\
5\end{array}$ & $\begin{array}{r}0.000 \\
-0.004 \\
-0.002 \\
-0.002 \\
-0.002\end{array}$ & $\begin{array}{l}-0.008,0.008 \\
-0.012,0.004 \\
-0.014,0.010 \\
-0.011,0.006 \\
-0.014,0.010\end{array}$ & $\begin{array}{l}-0.050 \\
-0.022 \\
-0.012 \\
-0.012 \\
-0.011\end{array}$ & $\begin{array}{l}0.960 \\
0.361 \\
0.725 \\
0.620 \\
0.734\end{array}$ & $\begin{array}{l}0.006 \\
0.005 \\
0.007 \\
0.005 \\
0.008\end{array}$ & $\begin{array}{r}0.001,0.001 \\
-0.001,0.010 \\
0.000,0.014 \\
0.000,0.011 \\
0.001,0.014\end{array}$ & $\begin{array}{l}0.051 \\
0.038 \\
0.058 \\
0.045 \\
0.064\end{array}$ & $\begin{array}{l}0.028 \\
0.118 \\
0.041 \\
0.067 \\
0.025\end{array}$ \\
\hline
\end{tabular}

MVPA, moderate-to-vigorous physical activity; $B$, unstandardized beta; $\beta$, standardized beta.

Model 1 = unadjusted; Model 2 = Model 1 plus maternal education, fat mass index, height and season change; Model $3=$ Model 2 plus pubertal status; Model 4 = Model 1 plus maternal education, International Obesity Taskforce group (reference normal), height and season change; Model $5=$ Model 4 plus pubertal status. ${ }^{*}$ All fruit and vegetable models are also adjusted for total energy consumption.

95\% CI $0 \cdot 046,2 \cdot 739 ; \beta=0 \cdot 040, P=0 \cdot 042)$ and Model 4 which used IOTF cut points $(\beta=0 \cdot 046, P=0 \cdot 001)$ but did not adjust for pubertal status. When Mean MVPA was the outcome patterns in the full sample were similar to the restricted sample with total energy and percentage energy from carbohydrate positively associated in all of the models, but percentage energy from fat was not associated in any of the models. For girls, fruit and vegetable consumption was associated with Mean MVPA in the unadjusted model (Model $1: \beta=0 \cdot 041, P=0 \cdot 029$ ) and Model 3 which included all possible confounders and pubertal status $(\beta=0.053, P=0 \cdot 024)$. Similar findings were evident when Weekday MVPA was the outcome. When Weekend MVPA was the outcome fruit and vegetable intake was associated with physical activity for the full sample of girls in the unadjusted model (Model 1: $\beta=0.042, P=0 \cdot 028)$ and the two models that adjusted for pubertal status (Model 3: $\beta=0 \cdot 049, P=0 \cdot 036$; Model 5: $\beta=0 \cdot 050, P=0 \cdot 033$; data not tabulated).

\section{Discussion}

In the current study we found that total energy, percentage energy from fat and percentage energy from carbohydrate were associated with physical activity among boys, while fruit and vegetable consumption was associated with physical activity among girls. However, all of the associations were weak $(\beta<0 \cdot 11)$. Moreover, although patterns were broadly similar when CPM, Mean MVPA and Weekday MVPA were the outcomes, there were no associations between diet and physical activity behaviours for boys when Weekend MVPA was the outcome. Analyses therefore show that there were weak, sex- and day (week/weekend)specific associations between an obesogenic diet and physical activity behaviours of a large sample of UK adolescents.

The associations between diet and physical activity reported herein are weaker than those reported for a small sample of 8- to 10-year-old African-American girls $^{(8)}$, young adults in the Bogalusa sample ${ }^{(9)}$ and US adults ${ }^{(26-28)}$. However, the participants' diets contained about $53 \%$ carbohydrate and $36 \%$ fat, which is broadly comparable to UK and US findings that have used $\mathrm{FFQ}^{(29,30)}$ and multiple $24 \mathrm{~h}$ dietary recalls ${ }^{(8,31)}$. Similarly, the mean minutes of MVPA obtained in this sample are broadly comparable to UK and US studies that have included children of a comparable age ${ }^{(32,33)}$. Collectively these findings may therefore suggest that the presence or absence of associations between diet and physical activity 
Table 5 Association between Weekend MVPA $(\mathrm{min} / \mathrm{d})$ and dietary variables in 11-year-old children (restricted, plausible reporters of dietary intake only), Avon Longitudinal Study of Parents and Children (ALSPAC), south-west England

\begin{tabular}{|c|c|c|c|c|c|c|c|c|c|}
\hline \multirow[b]{2}{*}{ Exposure } & \multirow[b]{2}{*}{ Model no. } & \multicolumn{4}{|c|}{ Boys } & \multicolumn{4}{|c|}{ Girls } \\
\hline & & $B$ & $95 \% \mathrm{Cl}$ & $\beta$ & $P$ & $B$ & $95 \% \mathrm{Cl}$ & $\beta$ & $P$ \\
\hline Total energy $(\mathrm{kJ})$ & $\begin{array}{l}1 \\
2 \\
3 \\
4 \\
5\end{array}$ & $\begin{array}{r}-0.003 \\
0.000 \\
0.000 \\
-0.001 \\
-0.001\end{array}$ & $\begin{array}{l}-0.006,0.001 \\
-0.004,0.005 \\
-0.005,0.006 \\
-0.005,0.003 \\
-0.007,0.004\end{array}$ & $\begin{array}{r}-0.037 \\
0.006 \\
0.004 \\
-0.014 \\
-0.015\end{array}$ & $\begin{array}{l}0.134 \\
0.838 \\
0.904 \\
0.626 \\
0.688\end{array}$ & $\begin{array}{r}-0.001 \\
0.001 \\
0.003 \\
0.000 \\
0.002\end{array}$ & $\begin{array}{l}-0.004,0.002 \\
-0.002,0.005 \\
-0.001,0.007 \\
-0.004,0.003 \\
-0.002,0.006\end{array}$ & $\begin{array}{r}-0.016 \\
0.019 \\
0.055 \\
-0.001 \\
0.038\end{array}$ & $\begin{array}{l}0.509 \\
0.502 \\
0.087 \\
0.981 \\
0.231\end{array}$ \\
\hline \% Energy from carbohydrate & $\begin{array}{l}1 \\
2 \\
3 \\
4 \\
5\end{array}$ & $\begin{array}{l}0 \cdot 166 \\
0 \cdot 137 \\
0 \cdot 142 \\
0 \cdot 183 \\
0 \cdot 186\end{array}$ & $\begin{array}{l}-0.026,0.358 \\
-0.059,0.332 \\
-0.130,0.414 \\
-0.013,0.380 \\
-0.088,0.459\end{array}$ & $\begin{array}{l}0.042 \\
0.035 \\
0.035 \\
0.047 \\
0.046\end{array}$ & $\begin{array}{l}0.089 \\
0.170 \\
0.306 \\
0.067 \\
0.183\end{array}$ & $\begin{array}{l}0.049 \\
0.069 \\
0.072 \\
0.088 \\
0.097\end{array}$ & $\begin{array}{l}-0.096,0.195 \\
-0.082,0.219 \\
-0.101,0.245 \\
-0.065,0.241 \\
-0.079,0.273\end{array}$ & $\begin{array}{l}0.016 \\
0.023 \\
0.024 \\
0.029 \\
0.032\end{array}$ & $\begin{array}{l}0.507 \\
0.370 \\
0.411 \\
0.257 \\
0.282\end{array}$ \\
\hline$\%$ Energy from fat & $\begin{array}{l}1 \\
2 \\
3 \\
4 \\
5\end{array}$ & $\begin{array}{l}-0.167 \\
-0.096 \\
-0.052 \\
-0.159 \\
-0.111\end{array}$ & $\begin{array}{l}-0.385,0.050 \\
-0.319,0.127 \\
-0.363,0.259 \\
-0.383,0.065 \\
-0.423,0.202\end{array}$ & $\begin{array}{r}-0.037 \\
-0.022 \\
-0.011 \\
-0.036 \\
0.024\end{array}$ & $\begin{array}{l}0 \cdot 131 \\
0 \cdot 398 \\
0 \cdot 741 \\
0 \cdot 164 \\
0 \cdot 486\end{array}$ & $\begin{array}{r}0.010 \\
0.001 \\
-0.025 \\
-0.016 \\
-0.047\end{array}$ & $\begin{array}{l}-0 \cdot 153,0 \cdot 173 \\
-0.168,0 \cdot 170 \\
-0.220,0 \cdot 171 \\
-0.188,0 \cdot 156 \\
-0.245,0 \cdot 151\end{array}$ & $\begin{array}{r}0.003 \\
0.000 \\
-0.007 \\
-0.005 \\
-0.014\end{array}$ & $\begin{array}{l}0.907 \\
0.989 \\
0.805 \\
0.855 \\
0.643\end{array}$ \\
\hline Energy density & $\begin{array}{l}1 \\
2 \\
3 \\
4 \\
5\end{array}$ & $\begin{array}{l}-0.604 \\
-0.505 \\
-0.212 \\
-0.604 \\
-0.202\end{array}$ & $\begin{array}{l}-1 \cdot 263,0.054 \\
-1 \cdot 190,0 \cdot 180 \\
-1 \cdot 135,0 \cdot 711 \\
-1.292,0.085 \\
-1 \cdot 132,0.727\end{array}$ & $\begin{array}{r}-0.045 \\
0.037 \\
-0.015 \\
0.044 \\
-0.015\end{array}$ & $\begin{array}{l}0.072 \\
0.149 \\
0.652 \\
0.086 \\
0.670\end{array}$ & $\begin{array}{r}-0.004 \\
-0.083 \\
-0.073 \\
0.010 \\
-0.132\end{array}$ & $\begin{array}{l}-0.494,0.486 \\
-0.439,0.605 \\
-0.687,0.541 \\
-0.520,0.539 \\
-0.756,0.492\end{array}$ & $\begin{array}{r}-0.017 \\
0.008 \\
-0.007 \\
0.001 \\
-0.012\end{array}$ & $\begin{array}{l}0.986 \\
0.754 \\
0.816 \\
0.971 \\
0.678\end{array}$ \\
\hline Fruit \& vegetables* & $\begin{array}{l}1 \\
2 \\
3 \\
4 \\
5\end{array}$ & $\begin{array}{l}0.006 \\
0.005 \\
0.005 \\
0.007 \\
0.005\end{array}$ & $\begin{array}{l}-0.003,0.015 \\
-0.004,0.015 \\
-0.009,0.018 \\
-0.003,0.017 \\
-0.009,0.019\end{array}$ & $\begin{array}{l}0.031 \\
0.028 \\
0.024 \\
0.036 \\
0.026\end{array}$ & $\begin{array}{l}0.218 \\
0.285 \\
0.491 \\
0.164 \\
0.460\end{array}$ & $\begin{array}{l}0.006 \\
0.004 \\
0.010 \\
0.005 \\
0.011\end{array}$ & $\begin{array}{r}-0.001,0.012 \\
0.004,0.011 \\
0.002,0.019 \\
-0.002,0.013 \\
0.002,0.020\end{array}$ & $\begin{array}{l}0.040 \\
0.026 \\
0.069 \\
0.034 \\
0.074\end{array}$ & $\begin{array}{l}0 \cdot 107 \\
0 \cdot 310 \\
0 \cdot 021 \\
0 \cdot 188 \\
0 \cdot 014\end{array}$ \\
\hline
\end{tabular}

MVPA, moderate-to-vigorous physical activity; $B$, unstandardized beta; $\beta$, standardized beta.

Model $1=$ unadjusted; Model $2=$ Model 1 plus maternal education, fat mass index, height and season change; Model $3=$ Model 2 plus pubertal status; Model 4 = Model 1 plus maternal education, International Obesity Taskforce group (reference normal), height and season change; Model $5=$ Model 4 plus pubertal status. ${ }^{*}$ All fruit and vegetable models are also adjusted for total energy consumption.

behaviours is unlikely to be a function of measurement and is more likely to be sample-dependent, differing by participant age, gender or perhaps country of study.

The weak associations between diet and physical activity behaviours suggest that while targeting change in both behaviours may be beneficial for obesity prevention, the benefit is likely to be a function of an accumulation of small changes rather than the product of a shared underlying construct. We found that associations between behaviours were consistent before and after adjustment for maternal education, a surrogate measure of socio-economic status, suggesting that socio-economic position is not a key underlying construct in understanding associations. Moreover, although associations differed by gender, the overall associations remained weak, suggesting that if diet and physical activity behaviours are influenced by an underlying construct then the effect is only very small. Thus, intervention effectiveness could be improved by finding ways to obtain small but achievable increases in physical activity, as well as small but achievable changes in dietary consumption, so that overall there is a change in energy balance and reduction in obesity. Obesity prevention interventions that include both diet and physical activity elements should therefore focus on the most effective method of changing each behaviour separately.
Over $20 \%$ of the participants under-reported their dietary intake, with girls providing more inaccurate reports than boys. These findings are slightly higher than the $21 \%$ of boys and $11 \%$ of girls in the same sample who provided under-reports at age 7 years ${ }^{(10)}$, suggesting that under-reporting may become a greater issue as girls grow up. Interestingly, mean minutes of MVPA per day and mean counts per minute were higher in the restricted sample than in the full sample, indicating that 'plausible' dietary reporters were more active than the misreporters. Identifying participants who provide implausible dietary records may be useful in delineating the factors that contribute to obesogenic dietary behaviours. Associations between diet and physical activity behaviours were comparable whether misreporters of diet were included or not in the analyses. Results therefore suggest that the associations between diet and physical activity behaviours are not related to dietary reporting status.

\section{Strengths and limitations}

The study used relatively robust measures to assess whether associations between diet and physical activity behaviours are evident before and after controlling for potential confounders. However, the study is limited by the gap between the two assessments, pubertal change 
between assessments and the fact that $59 \%$ of the diet and physical activity assessments were conducted in different seasons, which could have adversely affected the sensitivity of our assessments as physical activity has been shown to differ by time of year ${ }^{(34)}$. It is also important to recognize that physical activity patterns are not the same every day, with previous analysis of a subset of these participants indicating that the intra-individual intra-class correlation for accelerometer counts was $0.53^{(34)}$. To address potential limitations participants were only included in the analyses if they provided three or more days of accelerometer data and thus it is reasonable to assume that the accelerometer data provide a reasonable indication of habitual physical activity. It is also important to recognize that both the diet and the physical activity measures were designed to capture patterns of behaviour that are representative of usual life and we controlled for pubertal development and seasonal change in our analyses. It therefore seems reasonable to assume that if there were associations between diet and physical activity behaviours we should have been able to detect them despite the measures being collected 12 months apart. It is also important to recognize that a number of possible associations were examined in both boys and girls and therefore results need to be interpreted with caution, as it is possible that associations are a function of chance.

\section{Conclusions}

We found weak associations between the percentage energy from fat in the diet and physical activity behaviours of UK boys and between the fruit and vegetable intake and physical activity of UK girls. Moreover, we found that these associations were largely unchanged after excluding participants likely to have misreported dietary intake. Strategies that attempt to prevent obesity by small changes in both behaviours should focus on the most effective means of changing diet and the most effective means of changing physical activity separately.

\section{Acknowledgements}

The UK Medical Research Council, the Wellcome Trust and the University of Bristol provide core support for ALSPAC. The present research was funded specifically by a grant from the National Heart, Lung, and Blood Institute (R01 HL071248-01A), a grant from the Wellcome Trust (GR068049MA), and the World Cancer Research Foundation. We have no conflicts of interest. R.J. conceived the paper, performed the analysis and wrote the first draft of the paper. A.R.N. conceived the paper, advised on the analysis and provided critical content input. P.E. conceived the paper, led the dietary assessment and provided critical content input. C.M. supervised the accelerometer data collection and provided critical content input. L.J. supervised the dietary data collection and provided critical content input. C.J.R. conceived the paper, led the physical activity assessment and provided critical content input. We are extremely grateful to all the families who took part in this study, the midwives for their help in recruiting them, and the whole ALSPAC team, which includes interviewers, computer and laboratory technicians, clerical workers, research scientists, volunteers, managers, receptionists and nurses.

\section{References}

1. Whitaker RC, Wright JA, Pepe MS et al. (1997) Predicting obesity in young adulthood from childhood and parental obesity. $N$ Engl J Med 337, 869-873.

2. Jakicic JM (2002) The role of physical activity in prevention and treatment of body weight gain in adults. J Nutr $\mathbf{1 3 2}$, Suppl., 3826S-3829S.

3. Gillis LJ, Kennedy LC, Gillis AM et al. (2002) Relationship between juvenile obesity, dietary energy and fat intake and physical activity. Int J Obes Relat Metab Disord 26, 458-463.

4. Johnson L, Mander AP, Jones LR et al. (2008) Energy-dense, low-fiber, high-fat dietary pattern is associated with increased fatness in childhood. Am J Clin Nutr 87, 846-854.

5. Johnson L, Mander AP, Jones LR et al. (2008) A prospective analysis of dietary energy density at age 5 and 7 years and fatness at 9 years among UK children. Int J Obes (Lond) 32 , 586-593.

6. Tohill BC, Seymour J, Serdula M et al. (2004) What epidemiologic studies tell us about the relationship between fruit and vegetable consumption and body weight. Nutr Rev 62, 365-374.

7. Kipping RR, Jago R \& Lawlor DA (2008) Obesity in children. Part 2: Prevention and management. BMJ 337, a1848.

8. Jago R, Baranowski T, Yoo S et al. (2004) Relationship between physical activity and diet among African-American girls. Obes Res 12, Suppl., 55S-63S.

9. Jago R, Nicklas T, Yang SJ et al. (2005) Physical activity and health enhancing dietary behaviors in young adults: Bogalusa Heart Study. Prev Med 41, 194-202.

10. Glynn L, Emmett P \& Rogers I (2005) Food and nutrient intakes of a population sample of 7-year-old children in the south-west of England in 1999/2000 - what difference does gender make? J Hum Nutr Diet 18, 7-19.

11. Golding J, Pembrey M \& Jones R (2001) ALSPAC - the Avon Longitudinal Study of Parents and Children. I. Study methodology. Paediatr Perinat Epidemiol 15, 74-87.

12. Emmett P (2009) Dietary assessment in the Avon Longitudinal Study of Parents and Children. Eur J Clin Nutr $\mathbf{6 3}$, Suppl. 1, S38-S44.

13. Riddoch CJ, Mattocks C, Deere K et al. (2007) Objective measurement of levels and patterns of physical activity. Arch Dis Child 92, 963-969.

14. Puyau MR, Adolph AL, Vohra FA et al. (2002) Validation and calibration of physical activity monitors in children. Obes Res 10, 150-157.

15. Welk G, Schaben JA \& Morrow JR (2004) Reliability of accelerometry-based activity monitors: a generalizability study. Med Sci Sports Exerc 36, 1637-1645.

16. Mattocks C, Ness A, Leary S et al. (2008) Use of accelerometers in a large field-based study of children: protocols, design issues, and effects on precision. $J$ Phys Act Health 5, Suppl. 1, S98-S111.

17. Mattocks C, Leary S, Ness A et al. (2007) Calibration of an accelerometer during free-living activities in children. Int $J$ Pediatr Obes 2, 218-226. 
18. Cole TJ, Bellizzi MC, Flegal KM et al. (2000) Establishing a standard definition for child overweight and obesity worldwide: international survey. BMJ 320, 1240-1243.

19. Puyau M, Adolph A, Vohra FA et al. (2004) Prediction of activity energy expenditure using accelerometers in children. Med Sci Sports Exerc 36, 1625-1631.

20. Jago R, Watson K, Baranowski T et al. (2006) Pedometer reliability, validity and daily activity targets among 10 - to 15-year-old boys. J Sports Sci 24, 241-251.

21. Eto C, Komiya S, Nakao T et al. (2004) Validity of the body mass index and fat mass index as an indicator of obesity in children aged 3-5 year. J Physiol Anthropol Appl Human Sci 23, 25-30.

22. Abbott A, Balls EJ, O'Connor JO et al. (2002) The use of body mass index to predict body composition in children. Ann Hum Biol 29, 619-626.

23. VanItallie TB, Yang MU, Heymsfield SB et al. (1990) Heightnormalized indices of the body's fat-free mass and fat mass: potentially useful indicators of nutritional status. Am J Clin Nutr 52, 953-959.

24. Schofield WN (1985) Predicting basal metabolic rate, new standards and review of previous work. Hum Nutr Clin Nutr 39, 5-42.

25. Torun B, Davies PS, Livingstone MB et al. (1996) Energy requirements and dietary energy recommendations for children and adolescents 1 to 18 years old. Eur J Clin Nutr 50, Suppl. 1, S37-S80.

26. Matthews CE, Hebert JR, Ockene IS et al. (1997) Relationship between leisure-time physical activity and selected dietary variables in the Worcester Area Trial for Counseling in Hyperlipidemia. Med Sci Sports Exerc 29, 1199-1207.

27. Gillman MW, Pinto BM, Tennstedt S et al. (2001) Relationships of physical activity with dietary behaviors among adults. Prev Med 32, 295-301.

28. Simoes EJ, Byers T, Coates RJ et al. (1995) The association between leisure-time physical activity and dietary fat in American adults. Am J Public Health 85, 240-244.

29. Rugg-Gunn AJ, Fletcher ES, Matthews JN et al. (2007) Changes in consumption of sugars by English adolescents over 20 years. Public Health Nutr 10, 354-363.

30. Phillips SM, Bandini LG, Naumova EN et al. (2004) Energydense snack food intake in adolescence: longitudinal relationship to weight and fatness. Obes Res 12, 461-472.

31. Lytle LA, Ebzery MK, Nicklas T et al. (1996) Nutrient intakes of third graders: results from the Child and Adolescent Trial for Cardiovascular Health (CATCH) baseline survey. J Nutr Educ 28, 338-347.

32. Jago R, Anderson C, Baranowski T et al. (2005) Adolescent patterns of physical activity: differences by gender, day and time of day. Am J Prev Med 28, 447-452.

33. Basterfield L, Adamson AJ, Parkinson KN et al. (2008) Surveillance of physical activity in the UK is flawed: validation of the Health Survey for England Physical Activity Questionnaire. Arch Dis Child 93, 1054-1058.

34. Mattocks C, Leary S, Ness A et al. (2007) Intraindividual variation of objectively measured physical activity in children. Med Sci Sports Exerc 39, 622-629. 